\title{
Academic staff recruitment and retention challenges at the University of Botswana medical school
}

\author{
M Kebaetse, ${ }^{1 *} \mathrm{PhD}, \mathrm{PT} ;$ G G Mokone, ${ }^{1 *} \mathrm{PhD} ; \mathrm{L}$ Badlangana, ${ }^{1} \mathrm{PhD} ; \mathrm{L}$ Mazhani, ${ }^{2} \mathrm{MD}$ \\ ${ }^{1}$ Department of Biomedical Sciences, Faculty of Medicine, University of Botswana, Gaborone, Botswana \\ ${ }^{2}$ Department of Paediatrics, Faculty of Medicine, University of Botswana, Gaborone, Botswana \\ * Joint first authors.
}

Corresponding author: M Kebaetse (maikutlo.kebaetse@mopipi.ub.bw)

Background. Sub-Saharan Africa has a greater share of the global burden of disease, poverty, and inadequate human resources for health compared with other regions of the world. Botswana, like other regional countries, is failing to successfully recruit and retain academics at its medical school.

Objectives. To document the medical school's staff recruitment and retention trends and challenges, and to propose possible solutions. Methods. This was a descriptive research study involving review and analysis of the University of Botswana medical school's staff number targets, actual numbers on post, and other relevant publicly available university documents. The numbers and country of origin of staff recruited from 2008 to 2013 were recorded. Net staff gain or loss per year was then calculated. Student numbers were analysed and related to staff availability. As there was a multilevel change in university management in 2011, the periods and events before and after April 2011 were analysed. Publicly available University of Botswana documents about the university's organisational structure, policies, and processes were reviewed.

Results. Over a 5-year period, the school recruited 74 academics worldwide; 30 of them left the school. Retention was a greater challenge than recruitment. The school had difficulty recruiting locals and senior academics, regardless of specialty. It appears that staff loss occurred regardless of country of origin.

Conclusion. The authors suggest that multilevel change in management was one of the most likely contributors to the school's recruitment and retention challenges. The University of Botswana must comprehensively address these.

S Afr Med J 2016;106(7):730-734. DOI:10.7196/SAMJ.2016.v106i7.10482

The ability of nations to meet their development goals depends, among other factors, on resource availability and the magnitude of the challenges they face. There has been special focus on sub-Saharan Africa, in part because the region has a greater share of the global burden of disease, poverty, and inadequate human resources for health compared with other regions of the world. ${ }^{[1-4]}$ Researchers and global funding agencies alike have therefore warned that Africa will not be able to meet its Millennium Development Goals without an adequate and stable health workforce. ${ }^{[3,5,6]}$

A proliferation of new medical schools in sub-Saharan Africa that began in the 1990s, and a more recent increase in enrolment at most medical schools in the region, ${ }^{[6]}$ is perhaps one of the most important and strategic approaches attempted to help mitigate some of the region's health and manpower challenges. The thinking is that training a large number of doctors locally may in the long run help to increase the number of doctors working locally. ${ }^{[6,7]} \mathrm{A}$ major drawback and threat to the sub-Saharan nations' ability to transform the healthcare landscape at their respective local markets, however, is an inability to successfully recruit academics and retain them at local medical schools. ${ }^{[6-10]}$ Mullan et al. ${ }^{[6]}$ showed that half of the medical schools in sub-Saharan Africa had major staff shortages, poor recruitment, and substantial (6 - 18\%) academic staff loss over a 5 -year period. Poor salaries, poor infrastructure and equipment, heavy workloads, growing enrolment and other factors contributed to these problems.

Botswana, one of the most stable African democracies ${ }^{[11]}$ with an upper-middle-income economy, ${ }^{[12]}$ opened its first and only medical school in 2009. The investment was in part a recognition of: (i) the country's severe shortage of medical doctors: ${ }^{[7,13]}$ (ii) a failed external training strategy; ${ }^{[7]}$ and (iii) the country's contribution to sub-Saharan Africa's disproportionately high share of the global burden of disease, especially its high rate of people living with HIV/AIDS. ${ }^{[1,15]}$ Furthermore, the school received generous support from the US government through the Medical Education Partnership Initiative, which helped to accelerate its development.

Although serious concerns have been raised about staffing, recruitment, and retention of academics at medical schools in sub-Saharan Africa, there is a paucity of data on recruitment and retention of staff at these schools. Challenges faced in the recruitment and retention of academics at the University of Botswana School of Medicine (UBSOM), which did not exist at the time of Mullan et al.' $\mathrm{s}^{[6]}$ study, have not been documented and may be of interest to other new medical schools and countries that might be contemplating establishing new schools. This article reports on staff recruitment and retention trends at UBSOM over a 5-year period ending in December 2013. The university's organisational structure, relevant policies, procedures and leadership movements are described for their perceived or potential effect on recruitment and retention. ${ }^{[8,16-19]}$ The article concludes by proposing solutions.

\section{Methods}

We conducted descriptive research that involved review and analysis of the school's staff number targets, actual numbers on post, and other relevant publicly available university documents. Furthermore, we relied on first-hand knowledge about the school events and activities since its inception.

We recorded the numbers and country of origin of staff recruited and on post each year since 2008. From these numbers, we com- 


\begin{tabular}{|c|c|c|c|c|c|c|}
\hline Academic staff & 2008 & 2009 & 2010 & 2011 & 2012 & 2013 \\
\hline 31 December, $n$ (citizen, \%) & $2(50.0)$ & $19(32.0)$ & $29(24.0)$ & $35(29.0)$ & $48(25.0)$ & $44(27.0)$ \\
\hline Recruited per year, $n$ & 2 & 17 & 11 & 12 & 23 & 9 \\
\hline Leaving post per year, $n$ & 0 & 1 & 0 & 8 & 10 & 11 \\
\hline Net gain/loss per year, $n$ & 2 & 16 & 11 & 4 & 13 & -2 \\
\hline Total gain/loss, $n^{*}$ & 29 & & & 15 & & \\
\hline
\end{tabular}

Table 2. Staff on post by region of origin

\begin{tabular}{lll}
\hline $\begin{array}{l}\text { Region of } \\
\text { origin }\end{array}$ & $\begin{array}{l}\text { Pre-2011, } \\
\boldsymbol{n}(\%)\end{array}$ & $\begin{array}{l}\mathbf{2 0 1 3}, \\
\boldsymbol{n}(\%)\end{array}$ \\
\hline Botswana & $7(24.1)$ & $12(27.3)$ \\
Other - Africa & $8(27.6)$ & $22(50.0)$ \\
Outside Africa & $14(48.3)$ & $10(22.7)$ \\
Total & $29(100.0)$ & $44(100.0)$
\end{tabular}

puted the cumulative staff numbers, citizen percentages, and staff lost per year. We then calculated net staff gain or loss per year.

We considered the periods and events before and after April 2011, as there was a major multilevel change in university governance in 2011; leadership and management style could potentially affect recruitment and retention. We also reviewed publicly available university documents to better appreciate how decisions are made and resources are managed. ${ }^{[19]}$

We considered curriculum decisions, such as course offerings and revision of enrolment targets, which the school made during its initial 5 years of existence, to evaluate whether staff availability influenced such decisions.

Finally, since students' perceptions about recruitment and retention challenges could potentially affect enrolment, we recorded the numbers of new students enrolled each year since 2009. For each class, the number of students as of December 2013 was also recorded. From the initial and current student numbers for each class, we calculated the net percentage gain or loss. The gain represented students gained per year per class as a result of repeating or transferring into the programme. The loss represented students repeating, dropping out, or transferring out of the programme.

\section{Results}

Table 1 shows that by the end of each year the total number of staff on post grew from 2 in 2008 to 44 in 2013, with the most $(n=23)$ hired in 2012. During the period before and after the change in management, there was a net gain of 29 and 15 academics, respectively. Table 2 shows that since 2011, the number of citizen academics almost doubled from 7 to 12 , although, essentially, the citizen-to-noncitizen ratio (1:3) did not change. For the same period, the number of non-Batswana Africans almost doubled, making them 50.0\% of the total staff on post, while the number of non-Africans decreased considerably from $48.3 \%$ to $22.7 \%$ of total staff numbers.

Table 1 also shows that by the end of 2013, the school had lost 30 academics (40.5\%), 29

Table 3. Overall staff losses by region of origin, December 2013

\begin{tabular}{lllll}
\hline Region of origin & Total recruited, $\boldsymbol{n}$ (\%) & Total lost, $\boldsymbol{n}$ (\%) & Loss, \% & Overall loss, \% \\
\hline Botswana & $15(20.3)$ & $3(10.0)$ & 20.0 & 4.0 \\
Other - Africa & $35(47.3)$ & $12(40.0)$ & 34.3 & 16.2 \\
Outside Africa & $24(32.4)$ & $15(50.0)$ & 62.5 & 20.3 \\
Total & $74(100.0)$ & $30(100.0)$ & - & 40.5 \\
$\begin{array}{l}\text { *\% loss with regard to place of origin. } \\
\text { +Overall \% loss with regard to total number ever recruited (74 academics). }\end{array}$ & & \\
\end{tabular}

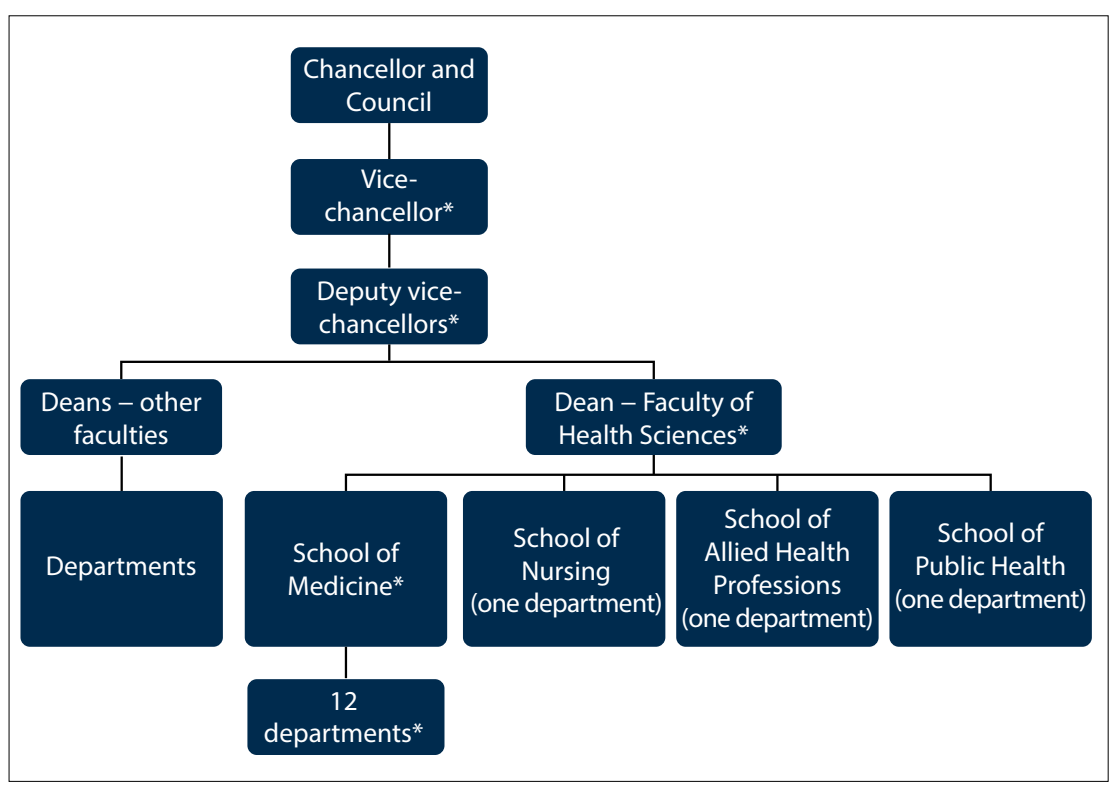

Fig. 1. UBSOM as depicted within the larger university organisational structure. UBSOM was situated within the Faculty of Health Sciences (FHS), one of the seven faculties. UBSOM was one of the four FHS schools, each with a head, and is depicted as having an extra layer in the process $\left({ }^{*}\right.$ represents levels where there was a change in management).

of whom left since 2011, with 2013 recording the greatest loss (11). Of all who left, 3 (10.0\%), $12(40.0 \%)$, and $15(50.0 \%)$ were Batswana, other Africans, and non-Africans, respectively (Table 3). Restated, Batswana, other Africans, and non-Africans who left comprised $4.0 \%$ (3 of 74 ), $16.2 \%$ (12 of 74 ), and $20.3 \%$ (15 of 74 ), respectively, of total staff ever recruited. In 2013 there was a net loss $(n=-2)$ of academics, while all previous years saw a net gain (Table 1 ).

Fig. 1 shows the medical school's organisational structure in the university. Within the
Faculty of Health Sciences each of the heads of department at UBSOM reported to the head of the medical school, who in turn reported to the dean, whereas for the other schools in the faculty each head of department was also the head of school and directly reported to the dean. For the other faculties, which did not have schools, the heads of department reported directly to their respective deans. The line of reporting then continued up the chain as shown, the vice-chancellor being the final appointing authority on matters of staff recruitment. 
Table 4. Students by year at UBSOM

\begin{tabular}{lllllll}
\hline Students & $\mathbf{2 0 0 8}$ & $\mathbf{2 0 0 9}$ & $\mathbf{2 0 1 0}$ & $\mathbf{2 0 1 1}$ & $\mathbf{2 0 1 2}$ & $\mathbf{2 0 1 3}$ \\
\hline At initial intake, $n$ & - & 36 & 48 & 50 & 50 & 50 \\
December 2013, $n$ & - & 36 & 45 & 40 & 55 & 53 \\
Gain/loss since initial intake, net \% & - & 0 & -6.2 & -20.0 & 10.0 & 6.0 \\
There was a change in management in 2011. & & & & & &
\end{tabular}

Except for the medical school, all schools or departments in the university enjoyed direct representation at all faculty committee structures; the 12 departments at the medical school were, however, collectively treated as a single department.

A number of important events occurred or prevailed before April 2011. First, the medical school was headed by a dean, who reported directly to deputy vice-chancellors. Second, to attract non-academic, but experienced specialist clinicians, especially citizens, a number of leadership positions (assistant and associate programme directors) were established. Finally, the university undertook a comprehensive stakeholder consultative process to reorganise academic structures to address, among others, institutional ineffectiveness, bureaucratic obstacles, and a lack of administrative and financial autonomy for deans (unpublished report - R Serpell, 2008); the restructuring was approved and to be effected starting in April 2011.

Beginning in April 2011 and over the next several months, a number of important events occurred. First, key management positions changed hands at essentially all levels of management, i.e. the university's chief executive officer (vice-chancellor), the deputy vice-chancellor of academic affairs, the dean of the Faculty of Health Sciences, the replacement of the position of Dean of the School of Medicine with Head of the School of Medicine, and the loss of the heads of department for Emergency Medicine and Paediatrics. Second, from mid-2011 until November 2013, several programme directors' contracts at the medical school were not renewed, leading to the departure of almost all of them. Finally, the new university management practically reversed restructuring plans.

Students were directly affected in a number of ways when the school failed to recruit academics. First, clinical rotations in Surgery, Psychiatry, and Obstetrics and Gynaecology planned for the pioneering (3rd year) students could not be offered. Second, as a result, the school was forced to modify the curriculum by reducing the number of rotations by one and extending the duration of each by 2 weeks. Third, there was uneasiness among all medical students, eventually leading to a week-long strike in early 2012, with students demanding that the nation address the staff shortage. Fourth, as Table 4 shows, although there was an initial intake of 36 students in 2009 and an increase of 12 students in 2010 as planned, the annual intake was capped at 50 students per year thereafter. Finally, the highest net loss $(20.0 \%)$ was recorded for the class initially

\section{Discussion \\ Recruitment and retention challenges}

It is noteworthy that during the 5-year period the young medical school managed to recruit 74 academics. While we did not ascertain academics motivation for choosing Botswana, the reasons may have included the country's political stability, ${ }^{[1]}$ its positive socioeconomic standing, ${ }^{[12]}$ the academics' pursuit of opportunities for personal and professional growth, and a spirit of altruism. ${ }^{[20]}$ The academics' rich variation in specialty, experience that included involvement in establishing new schools, and place of origin and training were all positive attributes from which the new school benefited.

Despite the relatively good recruitment, medical schools are notorious for having difficulty recruiting and retaining academic staff, especially highly qualified clinicians, ${ }^{[6,7,21,22]}$ and the combination of the two problems exacerbates staffing challenges. Consistent with previous reports that recruitment is resource intensive, ${ }^{[23]}$ UBSOM spent substantial amounts of time, money and other resources on advertising, reviewing and processing applications, staff relocation, and end-of-contract gratuity paid to expatriates at $25-30 \%$ of total salary earned. However, a major upsurge in 2011 - 2013 had an average staff loss of $\sim 10$ academics per year; only $12 \%$ of the total staff recruited were professors, with the last professorial appointment occurring before 2011; at best, the school met up to $55.2 \%$ (48 of 87) of its staffing target; 8 of 10 paediatricians left; and Master of Medicine programmes in Anaesthesiology, Public Health, enrolled in 2011. incoming staff occurred only in 2012, while and Emergency Medicine either collapsed or intake was suspended. Academic staff loss also meant loss of specialist clinical services to the community ${ }^{[6]}$ Therefore, the $40.0 \%$ overall staff loss during the 5-year period was much higher than the $6-18 \%$ previously reported for many medical schools in sub-Saharan Africa. ${ }^{[6]}$

Analysis of the school's recruitment trends showed that prior to April 2011 about 50.0\% of the staff came from outside Africa, predominantly developed countries, and after April 2011 a similar proportion came from other parts of Africa (outside Botswana), predominantly East Africa. Citizens, however, remained at $\sim 25.0 \%$ of total staff numbers. It might therefore be tempting to conclude that the school preferentially recruited from developed countries and East Africa, respectively, before and after the April 2011 change in management. This view is rather simplistic, as many dynamics that may require further research could have contributed to recruitment trends. The school was simply not successful at recruiting and retaining staff from any part of the world. Any attempt to recruit preferentially from a particular region may prove unsuccessful, given that staff loss occurred irrespective of place of origin.

Failure to recruit citizens is not unique to Botswana, as some regional medical schools rely on expatriates. ${ }^{[6]}$ Our results suggest that it may be easier to retain locals than nonlocals, as only $4.0 \%$ of total staff lost were Batswana. Some of the possible explanations are: (i) locals might be more financially and socially invested in the community than non-locals and therefore find it difficult to relocate; and (ii) factors that pull expatriates to Botswana might change at any time, making them quite mobile. We suggest that countries that fail to recruit or retain adequate numbers of citizens may risk being forever in the building phase.

\section{Possible contributing factors}

A number of factors might have contributed to, or help to explain, the recruitment and retention challenges experienced by UBSOM. First, salaries and benefits at the medical school were neither locally nor regionally competitive. Globally, there has been a high and growing demand for medical care, ${ }^{[9,24-26]}$ possibly contributing to the regional disparity in salaries at medical schools compared with private or public healthcare facilities and shrinking the pool from which to recruit specialists. The government paid much lower salaries to entry-level specialists at the medical school than at hospitals. ${ }^{[7]}$

Second, some staff may have left simply because their contracts ended or owing 
to staff discontent. The University of Botswana generally offers expatriates employment contracts of 2 - 5 years; therefore, some who joined the university in 2009 could leave in 2011. Indeed, some did not renew their contracts, but others abruptly terminated their contracts, suggesting that other factors might have been at play. Previous work on medical school faculty discontent and intent to terminate contracts showed that barriers to retention included discontent with deans and vice-chancellors about their lack of support, the lack of opportunity for academics to comment effectively on the leaders' performance, and inadequate recognition of clinical work in assessment and promotion criteria. ${ }^{[17]}$

Third, the multilevel change in management that began in April 2011 potentially unsettled the system, as processes and information flow could be interrupted, newcomers might have needed time to adjust to their new roles and organisational culture, and some leaders might not have adequately appreciated the enormity of challenges at the medical school. For example, there was a long period in 2011 (April - December) when appointments recommended by the school were not processed in the hierarchy of decision-making beyond the school. It is our view that the impasse can only be attributed to the change in management.

Fourth, the medical school was generally treated unfairly compared with other schools and faculties. For example, after April 2011 the university attempted to nullify programme director positions, and required a higher minimum qualification (associate professor) for the position of Head of School. Given the influence of governments, politics and culture in education and healthcare, ${ }^{[6,8]}$ the university might have lost the wisdom, experience, advocacy and boldness to challenge the system that locals could have brought.

Finally, since the restructuring had resulted in potential promotion or new roles for some managers, its reversal might have created embarrassment, confusion and uncertainty about senior university management, possibly adding to the school's inability to retain staff.

We argue that the abovementioned contributing factors, if not addressed, could jeopardise the investment made by the country and foreign donors, and make it difficult for the medical school to attract foreign funding.

\section{Effect on students}

Students were adversely affected by the events described above. The combination of: (i) a modified curriculum for 3rd-year students; (ii) the prolonged 2011 lack of progress on recruitment; and (iii) the 2011 staff loss, did not give students much confidence in the school's future and the university's ability to address staffing challenges. These events help to explain students' uneasiness, public expression of concerns about the school, week-long demonstrations, and ultimately the high drop-out rate for the 2011 cohort. Ten of the 50 students who enrolled in 2011 dropped from their group, with four repeating the year and the remaining six either quitting or leaving the university. The 1st-year students were the most negatively affected, probably because they were least invested in the programme and thus more likely to quit.

\section{Conclusion}

Over a 5-year period, the school was able to recruit $74(85.1 \%$ of total staff requirement) academics. The medical school was unsuccessful in recruiting and retaining academic staff, especially citizens and experienced clinicians, with retention being a greater challenge than recruitment. UBSOM therefore experienced one of the worst recruitment and retention challenges documented for medical schools so far. While salaries and other factors were possible contributors, the widespread multilevel change in management might have been destabilising and excessive for the medical school, thus adversely affecting recruitment and retention.

Given that many resources were spent on recruitment, but success was limited and retention was a greater problem irrespective of the staff's place of origin, it is highly likely that conditions of service or the work environment was not favourable.

A limitation of this study is that we did not survey academics to ascertain their reasons for staying or leaving. A future study will specifically address this concern.

\section{Proposed solutions}

The study's findings suggest that the following comprehensive recruitment and retention approach is needed:

- Given the medical school's standing as a project of strategic national interest, the government should help spearhead change.

- The Ministry of Health and the University of Botswana should share teaching and service responsibilities to help to reduce staff shortages on both sides.

- Multilevel change in management should be carefully considered and managed.

- The university should have a clear retention programme that includes structured mentoring and talent management.

- There should be aggressive local capacity building to substantially reverse the current citizen-to-expatriate ratio.

- To be competitive, the university should pay higher salaries, comparable with market rates, to professionals such as clinicians, biomedical scientists, and accountants.

- As increasingly high salaries may be unsustainable in the long term, the government and university should proactively seek and enter into private practice or other forms of income-generating agreements with all professionals.

Disclosure of funding. The writing of this manuscript was partly supported by the US President's Emergency Plan for AIDS Relief (PEPFAR)'s Medical Education Partnership Initiative through Health Resources and Services Administration (HRSA) grant number T84HA21125, which paid for MK to attend a workshop on writing for publication in SA, where parts of this manuscript were completed.

\section{References}

1. Lozano R, Naghavi M, Foreman K, et al. Global and regional mortality from 235 causes of death for 20 age groups in 1990 and 2010: A systematic analysis for the Global Burden of Disease Study 2010. Lancet 2012;380:2095-2128. DOI:10.1016/S0140-6736(12)61728-0

2. World Health Organization. The World Health Report 2006. Working together for health. http://www. who.int/whr/2006/whr06_en.pdf?ua=1 (accessed 25 May 2016).

3. Anyangwe SCE, Mtonga C. Inequities in the global health workforce: The greatest impediment to health 3. Anyangwe SCE, Mtonga C. Inequities in the global health workforce: The greatest impediment to health
in sub-Saharan Africa. Int J Environ Res Public Health 2007;4(2):93-100. DOI:10.3390/ijerph2007040002 in sub-Saharan Africa. Int J Environ Res Public Health 2007;4(2):93-100. DOI:10.3390/ijerph2007040002
4. World Health Organization. The global burden of disease 2010 study. http://www.who.int/pmnch/ 4. World Health Organization. The global burden of disease 2010 study.
media/news/2012/who_burdenofdisease/en/ (accessed 25 May 2016).

5. World Health Organization and Global Health Workforce Alliance. Scaling up, saving lives: Task force for scaling up education and training for health workers. Geneva: WHO and GHWA, 2008.

6. Mullan F, Frehywot S, Omaswa F, et al. Medical schools in sub-Saharan Africa. Lancet 2011;377:11131121. DOI:10.1016/S0140-6736(10)61961-7

7. Mokone GG, Kebaetse M, Wright J, et al. Establishing a new medical school: Botswana’s experience. Acad Med 2014;89(8 Suppl):S83-S87. DOI:10.1097/ACM.0000000000000329

8. Taferra D, Altbach PG. African higher education: Challenges for the 21st century. Higher Educ 2004;47:21-50. DOI:10.1023/B:HIGH.0000009822.49980.30

9. Burdick W. Challenges and issues in health professions education in Africa. Med Teach 2007;29:882886. DOI:10.1080/01421590701821695

10. Mufunda J, Chatora R, Ndambakuwa Y, Samkange C, Sigola L, Vengesa P. Challenges in training the ideal doctor for Africa: Lessons learned from Zimbabwe. Med Teach 2007;29:878-881. DOI:10.1080/01421590701813007

DOI: $10.1080 / 01421590701813007$
1. Van de Walle N. Africa’s range of regimes. J Democracy 2002;13(2):66-80

11. Van de Walle N. Africa’s range of regimes. J Democracy 2002;13(2):66-80.
12. World Bank Group. http://data.worldbank.org/country/Botswana (accessed 25 May 2016).

12. World Bank Group. http://data.worldbank.org/country/Botswana (accessed 25 May 2016).
13. World Health Organization. World Health Statistics 2012. Geneva: WHO, 2012. http://apps.who.int/ iris/bitstream/10665/44844/1/9789241564441_eng.pdf?ua=1 (accessed 25 May 2016).

14. World Health Organization. Global HIV/AIDS response: Epidemic update and health sector progress toward universal access. Geneva: WHO, 2011. http://whqlibdoc.who.int/ publications/2011/9789241502986_eng.pdf (accessed 25 May 2016).

15. World Health Organization. World Health Statistics 2013. Geneva: WHO, 2013. http://www.who.int/ gho/publications/world_health_statistics/2013/en/ (accessed 25 May 2016).

6. Bland CJ, Seaquist E, Pacala JT, Center B, Einstad D. One school's strategy to assess and improve the vitality of its faculty. Acad Med 2002;77(5):368-376. 
17. Lowenstein SR, Fernandez G, Crane LA. Medical school faculty discontent: Prevalence and predictors of intent to leave academic careers. BMC Med Educ 2007;7:37. DOI:10.1186/1472-6920-7-37

18. Schweitzer L, Eells TD. The forgotten faculty: Challenges for PhDs in clinical medical school departments. J Clin Psychol Med Settings 2008;15:7-11. DOI:10.1007/s10880-008-9095-x

19. Wynford-Thomas D. Organisation and management of medical schools: A survey of ten UK . Wynford-Thomas D. Organisation and management of medical schools: A survey of ten UK
universities. Medical Schools Council 2012. http://www.medschools.ac.uk/Publications/Documents/ universities. Medical Schools Council 2012. http://www.medschools.ac.uk/Publicat
Organisation_and_Management_of_Medical_Schools.pdf (accessed 25 May 2016).

20. Fee A, Karsaklian E. Could international volunteers be considered ethical consumers? A cros discipline approach to understanding motivations for self-initiated expatriates. In: Vaiman Haslberger A, eds. Talent Management of Self-Initiated Expatriates - A Neglected Source of Global Talent. Hampshire, UK: Palgrave and MacMillan, 2013:88-116.

21. Bickel J, Brown AJ. Generation X: Implications for faculty recruitment and development in academic health centers. Acad Med 2005;80(3):205-210. DOI:10.1097/00001888-200503000-00003

22. Scallan S. Education and the working patterns of young doctors in the UK: A review of literature. Med Educ 2003;37:907-912.
23. Wingard DL, Garman KA, Reznki V. Facilitating faculty success: Outcomes and cost benefit of the UCSD National Center of Leadership in Academic Medicine. Acad Med 2004;79(10):S9-S11. DOI:10.1097/00001888-200410001-00003

24. Bezuidenhout MM, Joubert G, Hiemstra LA, Struwig MC. Reasons for doctor migration from South Africa. SA Fam Pract 2009;51(3):211-215. DOI:10.1080/20786204.2009.10873850

25. Eastwood JB, Conroy RE, West PA, Tutt RC, Plange-Rhule J. Loss of health professionals from sub5astwood JB, Conroy RE, West PA, Tutt RC, Plange-Rhule J. Loss of health professionals from sub-
Saharan Africa: The pivotal role of the UK. Lancet 2005;365(9474):1893-1900. DOI:10.1016/S01406736(05)66623-8

26. Tankwanchi AB, Ozden C, Vermund SH. Physician migration from sub-Saharan Africa to the United States: Analysis of the 2011 AMA physician masterfile. PLOS Med 2013;10(9):1-27. DOI:10.1371/ annotation/64ffd514-00bb-4a5e-9e2e-584763637d14

Accepted 7 January 2016 